\title{
Q Una nacionalidad en consolidación y ¿ una ciudad en construcción. Festejos patrios en las primeras décadas de Mar del Plata
}

Ana Laura Lanteri ${ }^{1}$

\section{Introducción}

El estudio de la construcción de la nación es uno de los problemas Emedulares de la historiografía argentina. En los últimos años, el foco de atención ha sido puesto en la importancia de "lo simbólico" y de la participación del estado en dicho proceso. Esta nueva mirada reemplaza a aquella de sesgo economicista, que lo identificaba con el espacio dibujado por las relaciones de producción y de intercambio, cuyo carácter explicativo se ha debilitado. De igual modo, las tesis que afirman que la nación expresa una entidad anterior a su plena constitución, contenida tácitamente en una nacionalidad preexistente, han sido discutidas y complejizadas (Chiaramonte 1993, Terán 1994).

En el proceso de conformación de la nacionalidad argentina están imbricadas la constitución de una sociedad nacional y la redefinición del papel estatal. Respecto de este tema, el período comprendido entre 1880 y las primeras décadas del siglo XX resulta clave. En ese momento de grandes transformaciones, las autoridades nacionales comenzaron a impulsar la formación de la nacionalidad como un factor social aglutinante y como un instrumento de afirmación de la nación y su soberanía. Pero también como una herramienta de validación de su poder en un orden político restringido. Al mismo tiempo,

1 Becaria de CONICET -Categoría Interna de Posgrado Tipo I-. Integrante del Grupo de Investigación "Problemas y Debates del Sigl o XIX", Departamento de Historia, Facultad de Humanidades de la Universidad Nacional de Mar del Plata. Este trabajo presenta una síntesis del último capítul o de nuestra Tesina de Licenciatura: "La experiencia de una 'ciudad nueva' en el marco de una nacional idad en consolidación. Mar del Plata (1880-1916)", dirigida por la Dra. Valentina Ayrolo y realizada como Becaria -Categoría EstudianteAvanzado e Iniciación- de la Universidad Nacional de Mar de Plata, e-mail: analaura_lanteri@hotmail.com 
reconocieron que los rasgos constitutivos de dicha nacionalidad no estaban lo suficientemente fortalecidos, lo que los condujo a intensificar su accionar en dicha esfera.

Lo hicieron principalmente a través de un conjunto de mecanismos de acción, comunicación y control, entre los que se destacó la celebración de conmemoraciones patrióticas. Así, comenzó a inventarse una tradición apoyada en una simbología que, al actuar como un cohesionante de su sociedad y como un basamento de la legitimidad de la nación - que aún no estaba plenamente conformada- fue convirtiéndola en la patria (Terán 1994:33 y Bertoni 2001:12).

N uestro objetivo en este trabajo es mostrar como, en el marco de este proceso, las autoridades marplatenses encontraron en los festejos patrios un resquicio para consolidar su poder y definir una historia y una identidad para la ciudad que acababa de conformarse. Mar del Plata sufrió desde sus orígenes - conformada como pueblo en 1874 , con su primera autoridad en 1880 y declarada ciudad en 1906-, el impacto de la "ilusión burguesa" de fines de siglo XIX que se vio plasmada en su temprana conversión en villa balnearia de la élite (Bartolucci 2002:12).

Dicha excepcionalidad se vio favorecida porque la construcción de su estructura política se produjo en coincidencia con el proceso de consolidación del Estado nacional y en estrecha vinculación sociopolítica con la élite porteña; en momentos en que también se estaba conformando el ámbito municipal en Buenos Aires. Además la ciudad cambió rápidamente su perfil económico hacia el turismo para las familias de la clase al ta porteña y de otros puntos del país.

Las autoridades locales emplearon diversos recursos para solemnizar los festejos patrios, pero priorizaron y se sujetaron a las necesidades y urgencias de la comuna. Esta situación no fue percibida como la desatención de su tarea patriótica sino que, justamente, vehiculizaron la "argentinidad" intentando adaptarla a la situación municipal como una forma de afianzar su autoridad. La conformación del poder político marplatense estuvo enlazada a la construcción de un marco unificador de la identidad. 
Quinto Sol, № 13, 2009, ISSN 0329-2665, pp. 105-123

\section{Los festejos y la conformación del poder local}

\section{Vínculos entre las autoridades legislativas y educativas en una "ciudad nueva"}

Los festejos patrios, si bien son el fruto de una intencionalidad estatal uniformadora, no se constituyen en repeticiones porque cada generación con sus patrones le imprime nuevos sesgos. Como mecanismos utilizados para construir una memoria histórica facilitan la difusión de los elementos culturales y políticos que contribuyen a la conformación de una identidad. Sin embargo, también como entidades polirreferenciales, se desdoblan en una multiplicidad de relatos culturales que son apropiados con diferentes propósitos políticos. Se modifican así en la medida que cambia la manera en que son recepcionados y utilizados ${ }^{2}$.

En una Mar del Plata con las características que mencionaremos a continuación, se puede observar que los mandatarios vehiculizaron en los festejos patrios cuestiones asociadas a la necesidad de conformar y legitimar su autoridad. Como anticipamos, el período desde fines del siglo XIX a principios del XX, fue de redefinición de todas las esferas locales a la luz de su inserción en los procesos nacionales y provinciales.

La ciudad fue creciendo y complejizándose aceleradamente. De los mil habitantes con que contaba en 1881 pasó a superar los 25.000 hacia 1920, entre los cuales hubo una gran presencia de inmigrantes (alrededor del 40\%). Este crecimiento conllevó una rápida urbanización ya que sumó a su rol de núcleo de intercambios con el espacio rural - que la hermanaba con otras ciudades del ámbito pampeano-, el de balneario elegante de las clases altas (Da O rden 2003:1). Este proceso estuvo ligado además al ocaso de la actividad saladeril, a la rápida transformación de tierras en lotes urbanos, a la incorporación de infraestructura en transportes y comunicaciones y al impulso de la construcción y la hotelería (Jofré, Da O rden y Pastoriza 1991:93).

El crecimiento económico y la ampliación social contrastaron con los vaivenes políticos, dado que la autonomía política local se vio condicionada frente a la injerencia del gobierno bonaerense. D os grupos formaron parte de esta dinámica de crecimiento. Un primer núcleo de

2 PierreNora (1997) señala que la memoria no es una construcción espontánea si no que implica la instrumentalización del pasado en el presente de una comuni dad. 
población transitoria y de filiación europeizante, a los que se sumó la dirigencia local, fue el que aportó capitales e ideó los nuevos contornos de la ciudad. El otro sector, estuvo constituido por aquella población permanente que materializó los proyectos e ideales del primer grupo, mientras aprovechaba también las oportunidades que le brindaba una sociedad en formación y expansión (Álvarez y Reynoso 1991:75).

El conservadurismo, representado en $\mathrm{M}$ ar del Plata por familias de origen predominantemente nativo y en su mayoría propietarios rurales y con vinculaciones en la provincia y en la nación, estuvo en el poder en el período estudiado. Entre 1880 y 1886 - año en que Buenos Aires sancionó la Ley O rgánica Municipal que permitió la elección del primer Intendente en 1890- la presidencia del poder legislativo local estuvo a cargo del Juez de Paz, quien reunió entonces las atribuciones judiciales, ejecutivas y legislativas. En 1893, después de una revolución encabezada por los radicales, el gobierno fue intervenido mientras que, de 1895 a 1902, se mantuvo la continuidad electoral en el distrito. Este sistema presentó irregularidades por lo que el gobierno provincial implantó desde 1903 hasta 1916 a los "comisionados municipales", interventores que reemplazaron a los intendentes.

El complejo contexto nacional que implicó la consolidación institucional en el marco de un régimen político excluyente y cambios socioeconómicos derivados de la inmigración masiva y de la inserción del país en el mercado mundial, dio lugar a tensiones. Por ello fue funcional para al Estado nacional precisar un modelo municipal que aceptara la división entre una esfera política y otra administrativa. Los postulados de Juan Bautista Alberdi fueron la base de la definición del municipio "moderno" como un órgano despolitizado, subordinado a las políticas dictadas por la provincia y la nación y donde la "autonomía" se correspondía con el manejo económico y administrativo de la institución local (Ternavasio 1991).

En el marco de la competencia por la definición de los ámbitos de poder en esta estructura política municipal en construcción, existieron desacuerdos entre el poder legislativo y el educativo por las atribuciones que le competían a cada uno ${ }^{3}$. Prestemos atención a la

3 En otro trabajo hemos anal izado las relaciones de poder al interior de la élite dirigente marplatense enfatizando en un doble juego de tensiones y adaptaciones reflejo del problema de la construcción de la estructura política local. Ana Laura Lanteri, "Entrelo municipal, lo provincial y lo nacional. Relaciones de poder y prácticas nacionalizantes de las autoridades de una 'ciudad nueva' (Mar del Plata, 1880-1916)", sitio el ectrónico historiapolitica.com, patrocinado por el Programa Buenos Aires de Historia Política y dirigido por Luis Alberto Romero http://historiapolitica.com/datos/biblioteca/lanteri.pdf. 
siguiente discusión que es ejemplo de la tensión a la que nos referimos. En 1892, el Consejo Escolar solicitó al Concejo Deliberante que abone una cuenta por masas, chocolates y un empleado contratado con motivo de los festejos del 9 de julio en un colegio. En el recinto legislativo se suscitó un amplio debate al respecto.

Un funcionario expresó que el Consejo Escolar no había pedido autorización para dicho gasto y que la M unicipalidad contribuía con el $15 \%$ de sus rentas al sostenimiento de la educación, por lo que podían ser pagados con esos fondos ${ }^{4}$. El presidente coincidió y agregó que había querido contribuir a una mejor celebración, sin haberlo logrado por la falta de recursos.

Pero lo que más molestó a los concejales fue que hayan querido darles una "lección inaceptable de patriotismo histórico". Si sólo el Estado podía decretar recepciones oficiales y las M unicipalidades eran sus representantes, les correspondía a éstas ese derecho. Luego otro concejal sostuvo que le parecía más moral y caritativo reservar esos fondos para asistir a enfermos pobres ${ }^{5}$. Finalmente se resolvió no dar lugar al pedido.

Las autoridades legislativas definieron así su esfera de acción y sus prioridades en relación a las del principal organismo educativo de la ciudad, que dependía directamente de la provincia. Por ello creyeron conveniente destacar su dominio al ser "los" representantes del Estado argentino. Sintieron que habían interferido en sus funciones e incluso habían pretendido aleccionarlos, sin ser esa su atribución sino sólo la de velar por el desarrollo de la educación.

En este sentido, las palabras referidas a la contribución que ya destinaban a educación y la imposibilidad de afrontar mayores gastos para actos festivos, ilustran la intención de las autoridades políticas marplatenses de defender sus atribuciones en materia económica y administrativa. Este hecho no fue visto como la desatención de su tarea patriótica, sino como una oportunidad provechosa para legitimar su poder, como ampliaremos a continuación.

4 Recordemos que según la normativa de la época, correspondía a la Municipalidad donar terrenos para la edificación escolar y contribuir al sostenimiento de la educación con el $15 \%$ (al menos) de sus rentas totales. Ley 988 Regl amentación de la Educación Común, Buenos Aires de 14/9/1875. Digesto Escolar de la Provincia de Buenos Aires. Compilación de las Disposiciones legales y reglamentarias en vigencia por Arturo H. Massa, La Plata, 1905:207-233.

5 Biblioteca de Referencia Legislativa del Concejo Deliberante de Mar del Plata, Municipalidad de General Pueyrredón, Mar del Plata, Actas Liminares del Concejo Deliberante, 30/9/1882. En adelante $B R L, A L$. 


\section{Autoridades y sectores sociales: en busca de legitimidad política}

Las autoridades comunales debieron atender a los conflictos que se suscitaron y a la par, se preocuparon porque su poder fuese validado por la población y para ello se sirvieron de los festejos patrios. A los inconvenientes surgidos por la escasez de recursos en el erario municipal, se anexaron urgencias derivadas del ordenamiento urbano y otras relativas al bienestar general de la población que las autoridades consideraron prioritarias al momento de dichos festejos ${ }^{6}$. Mar del Plata era una ciudad "nueva" pensada y construida desde el Estado liberal y moderno. Los siguientes hechos, que fueron recurrentes en el período, son ilustrativos del estado de cosas que pretendemos exponer.

A principios de la década de 1880, el Capellán de la ciudad solicitó fondos para celebrar el Te Deum del 25 de Mayo. Un concejal afirmó que en el cementerio público se estaba construyendo un osario y se debía pensar en el gasto que ocasionaba, por lo tanto bastaba con una misa ${ }^{7}$. O tra nota de fines del período en estudio, abona nuestra presunción. En ella el Concejo Deliberante se dirigió a la Intendencia solicitando que se rompiese con la "anacrónica práctica del Te Deum", porque importaba a la comuna una erogación que no se condecía con "el espíritu eminentemente liberal de la mayoría de la población"8. De esta manera, se anteponía una visión moderna y laica del funcionamiento social.

Para tiempos anteriores al analizado en este artículo, se ha asegurado que el papel reservado a la élite en los festejos fue ambiguo, por las diferencias que existieron entre sus celebraciones más privadas y aquellas ofrecidas al pueblo. En los festejos populares pretendieron borrar las diferencias como una forma de expresar la sociedad republicana (Myers 1999:131). La comparación con el caso que nos ocupa es conveniente.

Con el fin de cumplir con la consolidación de la nacionalidad se desplegaron diversas acciones, entre las que se destaca la ejecución

6 Existieron también muchos casos de deudas que la Municipalidad mantuvo con la Dirección General de Escuelas. Algunos ejemplos en BRL, AL, 6/6/1885, 18/7/1899, 1/5/1882, 11/8/1884, 22/12/1884, 20/9/1886, 3/7/1894 y 30/5/1889.

7 Luego de un largo debate finalmente se acordó la suma pedida por el Capellán. BRL, AL 20/5/1882.

8 Archivo Histórico Municipal Villa Mitre, Mar del Plata, Expedientedel Departamento Deli iberativo 17/5/1913 (sin numerar). 
de un elenco de elementos lúdicos y de diversión. Los datos analizados dan cuenta, especialmente, del uso de pirotecnia, del acompañamiento en las celebraciones por bandas musicales y grupos de danza, de la realización de corridas de sortijas y del establecimiento de bazares con sorteos. De igual manera, solían repartirse folletos alusivos que en su mayoría contenían biografías o cronologías de las personas a las que se rendía homenajes.

Dentro de esta mecánica, las autoridades participaron sobre todo con el sostén económico ya sea a través de subvenciones o mediante el costeo parcial o total de los gastos. Lo hicieron garantizando, por ejemplo, que los premios estuviesen en relación a las ventas de las rifas o incluso estableciendo bazares cuya recaudación destinaban a la celebración de los festejos. Pero también se dieron un espacio para reforzar sus lazos internos al celebrar galas musicales o cenas exclusivas ${ }^{10}$.

La población marplatense encontró un motivo de reunión mientras que las autoridades aprovecharon esas ocasiones como espacios para que internalizaran las pautas sociales pretendidas. La participación de los escolares en los desfiles por las calles principales de la ciudad resultó ser un instrumento eficaz para movilizar el entusiasmo popular, al igual que en otros espacios de la provincia. O rganizados en batallones escolares los niños asumían los deberes cívicos y militares de la nación, que desde el Estado nacional se pretendían instaurar (Bertoni 2001:89-95).

Un historiador local nos brinda un testimonio al respecto:

“QQué veinticincos de Mayo! ¿Qué nueves de julio! Disparos de bombas al amanecer, en tanto que la Banda de M úsica recorría las calles despertando con dianas a los vecinos que luego concurrían en masa a la plaza, enfrentando al Palacio Municipal. No desfilaban entonces batallones sino escolares"11.

La misión pedagógica de los festejos estuvo especialmente vinculada con la gran presencia de población extranjera en la ciudad. Para el poder municipal también fue central el problema de la inserción

9 BRL, AL 1/5/1881, 27/6/1881, 21/6/1886, 28/6/1886, 10/8/1887, 13/9/1887, 27/10/1888, 12/2/1892, 22/2/1892, 21/6/1913, 27/6/1913. Para más datos sobre las bandas musicales marplatenses ver especial mente Diario La Capital, Edición especial Bodas de Oro, Mar del Plata, 25 de mayo de 1955:85.

10 Por citar al gunos casos, ver BRL, AL 3/7/1894 y 13/5/1881.

11 “Don Braulio en Mar del Plata”, en Barili (1964:497). 
sociopolítica de los inmigrantes. Ha sido señalado que fue relativamente fácil para éstos lograr posiciones de prestigio y reconocimiento en la ciudad y que para ello apelaron a una identidad común de origen, sirviéndose de diversos festejos. Por ejemplo en el caso de las "Romerías", los españoles convocaban a las autoridades locales, provinciales y nacionales y optaban por hacer el festejo en el mes de febrero y frente al hotel "Bristol", uno de los espacios de sociabilidad preferidos de dichas autoridades.

Para la élite nativa, festejos populares de este estilo eran importantes en el marco de su interés por afirmar su poder y modernizar las prácticas públicas de acuerdo con la ideología de "progreso" que por entonces era dominante. Por ello, con el tiempo comenzaron a hacer donativos para su desarrollo (Da O rden, 2003 y 2005), aunque también intentaron reglamentarlos, determinando por ejemplo el uso de la simbología patria en una posición dominante. Así, en 1892 se redactó una ordenanza en la ciudad que estableció que en las manifestaciones populares la bandera argentina ocuparía la derecha 0 el centro, según fuera acompañada de una o más banderas respectivamente; además las colectividades que desearan celebrar alguna conmemoración debían solicitar el permiso correspondiente a la Intendencia y pedir la aprobación del plan de adorno y del programa respectivo ${ }^{12}$.

Profundizaremos ahora en el carácter y la historicidad del tema a partir de un paralelismo entre los festejos de dos "Centenarios" desarrollados en la década de 1910.

\section{Dos Centenarios, una misma intención y dinámica}

En este apartado presentaremos al gunas notas sobre los festejos del Centenario de la "Revolución de Mayo" en 1910 y del Centenario del natalicio de Patricio Peralta Ramos en 1914, considerado el fundador de la ciudad ${ }^{13}$. Hacia los años diez la diversificación socio-económica a

12 BRL, AL 8/11/1892. Hemos hal lado otro ejempl o el ocuente: hacia 1916 fueron regl amentados los disparos de bomba siendo permitidos únicamente los días patrios y de festividades que la Intendencia creyera oportuno. BRL, AL 30/10/1916.

13 Patricio Peral ta Ramos compró campos aJ oséCoelho de Meyrelles en 1860 en los que intentó revitalizar el saladero y en los que introdujo mejoras técnicas. En 1873 inició la gestión para fundar el Pueblo de Mar del Plata anteel gobernador deBuenosAires, hecho quetuvo lugar en 1874. Para una biografía ver Barili 1991. 
la que aludimos había promovido la emergencia de trabajadores urbanos y de sectores medios o en ascenso, que complejizaron el escenario local, por la multiplicación de entidades intermedias y por el pluralismo político-partidario que permitió al socialismo liderar el gobierno municipal durante casi una década desde 1920 (Da O rden 2003).

En este marco, los festejos de ambos Centenarios fueron pensados por las autoridades marplatenses como momentos de inflexión en los que ratificaron su deber de solemnizar dos hechos trascendentes: uno de la historia nacional y otro de la municipal. En un contexto cambiante encontraron un espacio propicio para legitimar su autoridad y construir una identidad y una historia para la novel ciudad.

\section{0: Mar del Plata celebra a la nación}

Ha sido reiteradamente destacado que el año 1910 marcó un quiebre político en el país y un giro en su sistema educativo. Se inscribió en la historia nacional como un momento de balance y de búsqueda de soluciones a los conflictos originados por el creciente proceso modernizador: Argentina se "mostraba" al mundo. En ello era una cuestión primordial la defensa de la integridad y de la soberanía argentina, las que dependían de la coherencia interna que las élites pudiesen mantener (Ferrás 2003). Hacia principios de siglo el movimiento por lo patriótico y la administración escolar cobraron una sistematicidad mayor, sobre todo gracias al accionar de José María Ramos M ejía como Presidente del Consejo Nacional de Educación.

En este marco, Buenos Aires por su protagonismo tanto en la gesta revolucionaria como en el proceso económico visualizado en la prosperidad que había alcanzado por aquel entonces en el país, condensaba los atributos de la nación a la que se le rendía homenaje (Príncipe 2003). En Mar del Plata, del análisis de la documentación, surge que las autoridades se hicieron eco de los ritmos provinciales al festejar este acontecimiento con el mayor esplendor posible.

Los gastos ocasionados por el programa para la celebración en los colegios de las provincias debieron ser sufragados por los vecinos de cada localidad $^{14}$. No poseemos datos que confirmen el desarrollo de

14 El mismo incluyó entre otras actividades: I Monumento al "Maestro de Escuela”, II Exposición Escolar, III Museo Histórico Escolar, IV Proyecto de ley sobre ampliación de edificio del Concejo, V Monografía históricas, VI Bautizo de escuelas, VII Conferencias Pedagógicas, 
las diversas actividades pautadas pero sabemos que se construyeron los locales de las escuelas números $7,8,11,12,13$ y 17. Ello porque la Dirección General de Escuelas de la Provincia, respondiendo al plan de festejos, hizo que todos los locales tuviesen las mismas características materiales, siendo construidos en madera y chapas de zinc.

Por otra parte, la conmemoración excedió el ámbito educativo y se desplegó en toda la ciudad. Bajo el argumento de que era "el deber del pueblo y de las autoridades solemnizar debidamente el próximo centenario de nuestra emancipación política" se nombró una Comisión - presidida por Julio César Gascón ${ }^{15}$ - para organizar el programa conmemorativo. De igual manera, se resolvió que la Intendencia debía facilitarles todos los elementos necesarios para el mejor desempeño del cometido, para lo que puso a disposición el personal de las cuadrillas y los instrumentos de trabajo ${ }^{16}$. También se estableció que el Palacio M unicipal fuese iluminado las noches del 21 al 25 de Mayo quedando los gastos a cargo de la Intendencia ${ }^{17}$.

Sin embargo a los ritmos nacionales y provinciales se le sumaron algunos compases locales. Nuevamente incidió la precaria situación económica local. Por ejemplo, el Municipio pidió disculpas por no poder hacerse cargo del presupuesto para el transporte de un kiosco ${ }^{18}$. Asimismo, en el debate que tuvo lugar en el recinto legislativo un funcionario agregó que no obstante sus deseos, la Intendencia se debía a las diversas exigencias de los servicios municipales, por lo que muy a

VIII Festivales escolares, IX Monografías sobre educación en la RepúblicaArgentina, X Concurso de lectura, aritmética, ortografía e Historia argentina, entre los al umnos de las escuelas de Capital Federal, provincias y teritorios nacionales, XI Reseñas históricas. Digesto de Instrucción Primaria. Leyes, decretos y resoluciones vigentes para las escuelas y dependencias del Consejo Nacional de Educación, Buenos Aires, 1920, Exp. 396. 14/1/1910 y Exp. 595. 20/1/1910. En adelante, Dig. Inst. Prim.

15 Fue Consejero Escolar desde 1880 hasta 1890 e I ntendente entre 1916 y 1917.

16 Archivo Histórico Municipal Villa Mitre, Mar del Plata, Libro copiador cartas y notas al Intendente Decreto del Comisionado Municipal, 25/2/1910. En adelante, Copiador.

17 Copiador, Nota del Secretario de la Intendencia al Gerente de la Compañía de Electricidad “Del Plata", 16/5/1910. I gual mente encontramos que el Intendente solicitó autorización para reforzar la Partida de Fiestas Públicas con una suma de 12.000 pesos moneda nacional por el Centenario y cualquier otra fiesta patria. Esta cuestión despertó un nuevo debate aunque no sabemos si fue aprobada. Copiador, Nota del Comisionado Municipal al Ministro deGobierno dela Provincia, 15/3/1910.

18 Copiador, Nota del Comisionado Municipal al Presidente de la Comisión del Centenario, 9/6/1910 y Nota del Comisionado Municipal al Ministro de Gobierno de la Provincia, $15 / 3 / 1910$. 
pesar suyo no podía disponer de una suma que respondiese ampliamente a las actividades proyectadas ${ }^{19}$. Al final, la suma consignada para la celebración fue de 10000 pesos moneda nacional, un monto elevado si se lo compara con los 4300 que se presupuestaron en 1914 para el pago de los sueldos del Poder Ejecutivo y Legislativo ${ }^{20}$.

Además, las autoridades se sivieron de otros instrumentos materiales y simbólicos, como la instauración de monumentos y el nomenclátor urbano para engalanar la celebración ${ }^{21}$. En 1909 un grupo de vecinos se dirigió al Comisionado municipal con la intención de colaborar en la organización de los festejos y le solicitaron que se denomine "Avenida de Mayo" a la que por entonces recorría la ciudad desde la Plaza Pueyrredón - en donde años atrás se había instaurado un monumento de Juan Martín de Pueyrredón quien dio nombre también al Municipio del que la ciudad era y es cabecera- hasta la Explanada ${ }^{22}$. También pidieron autorización para colocar un monumento levantado por suscripción popular.

La Comisión que la Intendencia designó para estudiar la propuesta adujo que recibía con amplia simpatía "el patriótico proyecto" y destacó que el lugar elegido para emplazarlo -el paraje "Punta Piedras"-, por estar frente al océano, daría al homenaje la "majestad y grandeza de las glorias" que consagraba. Asimismo, sugirió que se llamase "Avenida de Mayo" a todo el Boulevard marítimo y no sólo a la parte propuesta por los vecinos, para dar mayor amplitud a la conmemoración. Finalmente recomendó que la colocación de la pie-

19 Copiador, Nota del Comisionado Municipal al Presidente de la Comisión del Centenario, 9/3/1910.

20 Archivo Histórico Municipal Villa Mitre, Mar del Plata, Expedientes del Departamento Deliberativo (fondo abierto), Presupuesto de 1914. Lamentablemente no contamos con el presupuesto de 1910.

21 Para ampliar estetema ver Lanteri 2007.

22 Juan Martín de Pueyrredón reci bió un trato especial de las autoridades marplatenses. Fue presentado general mentea la par deotros suj etos como San Mart́n y Bel grano. BRL, AL 5/5/1893 y 13/3/1895. También se recibió un retrato de Pueyrredón donado por Adolfo Carranza - por entonces di rector del Museo Nacional- como parte de una gestión en la que obsequió a los diversos Partidos de Campaña de la provincia que llevaban nombres de los que consideraba "fundadores de nuestra nacional idad". En la correspondencia manteni da entre el Intendentey esta persona, entre otras cuestiones, el primero propuso fechas para el acto, solicitó datos para la confección de los folletos y Carranza se comprometió a asistir al acto. Consideramos a este ejempl o como clara muestra de la vinculación de las autoridades locales y provinciales en el proceso de construcción dela nacional idad. BRL, AL y Barili (1964:292-294). 
dra fundamental del monumento fuese incluida como un número del programa de los festejos.

Las autoridades requirieron de la población, no sólo el sostén pecuniario, sino también la participación activa como asistentes y organizadores, como vimos en los ejemplos. El uso del espacio público permitía la mediación entre la sociedad y las autoridades. Así, por detrás del espacio físico en el que se emplazaron las calles y monumentos, la intención principal residía en la elaboración de una nueva memoria histórica a partir de la selección de personas y hechos del pasado y su posterior representación material en estos dos elementos.

En la provincia de Buenos Aires se pretendió que la participación popular en los festejos fuese reducida a la figura del "espectador" (Príncipe 2003). Sin embargo en Mar del Plata, al igual que en otras ciudades como Rosario, se realizó una gran manifestación cívica. Basta como ilustración la siguiente fotografía en donde se aprecia el gran caudal de asistentes y la centralidad adquirida por los escolares, a la que ya hemos referido.

Procesión cívica. Mar del Plata, 25 de mayo de 1910.

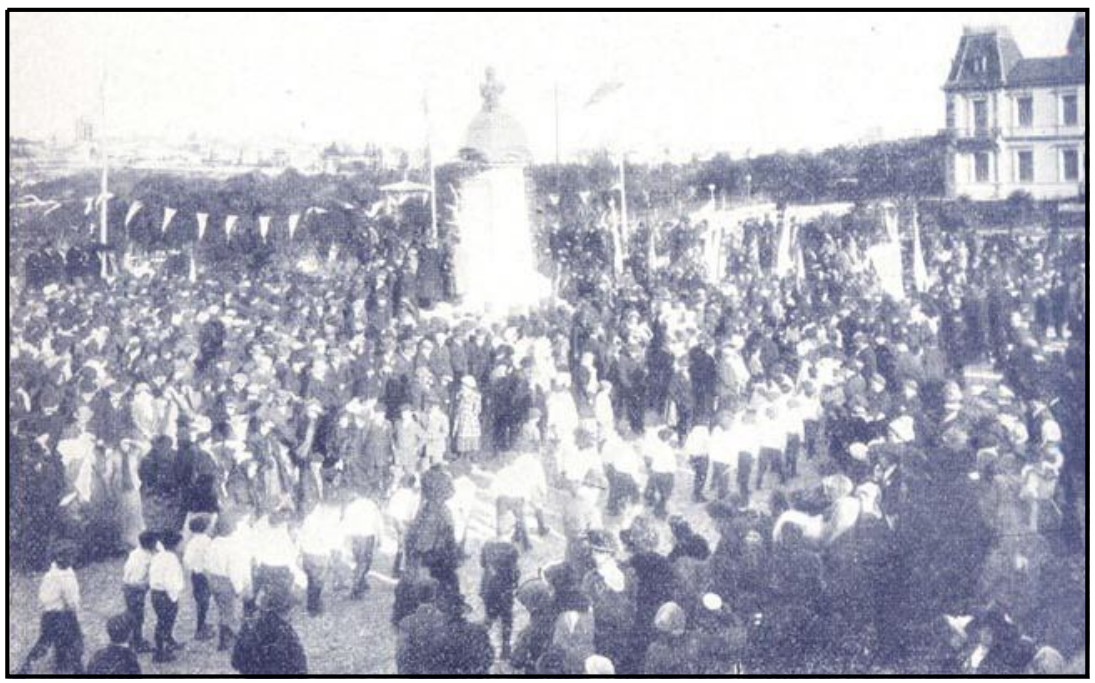

Fuente: Revista Caras y Caretas, Año XIII, № 610, 11 de junio de 1910.

En Rosario el programa conmemorativo bonaerense fue rechazado porque sus propuestas fueron consideradas monumentales e inadecua- 
das al espíritu local y, la creación de un hospital bajo la suscripción pública, fue el acontecimiento central. Ha sido destacada la intencionalidad de la élite rosarina de mostrar hacia adentro y afuera el crecimiento de la ciudad y su ventajosa ubicación como puerto comercial. La manifestación cívica y el hospital condensaban sus val ores más preciados: progreso, ciencia, iniciativa privada, prosperidad, convivencia y caridad. En 1910, Rosario se alineaba en el relato histórico fundante de la nación como aquella ciudad cuna de la bandera y del bautismo de fuego de San M artín en San Lorenzo (Príncipe 2003).

Por su parte, las autoridades marplatenses no podían incorporar a la ciudad en la gesta nacional dada su reciente creación. A pesar de ello, argumentaron que se encontraba en un lugar de privilegio en el concierto argentino contemporáneo. El festejo del centenario del nacimiento de Patricio Peralta Ramos - producido cuatro años después que el de la "Revolución de M ayo"- fue un acontecimiento que aprovecharon en dicho sentido.

\section{4: Mar del Plata se celebra a sí misma}

También aquí apelaron al nombramiento de calles y a un monumento para glorificar a Patricio Peralta Ramos y, de la misma forma que en 1910, las finanzas y urgencias del contexto marplatense matizaron el festejo. Como parte del programa conmemorativo se había estipulado la construcción de un monumento, pero en el recinto municipal dos concejales se opusieron tenazmente argumentando que no era digno dedicar tiempo a cuestiones de esa naturaleza cuando graves asuntos esperaban "la dedicación atenta y laboriosa del Concejo", como la deuda contraída con la usina de electricidad. Pese a las resistencias se resolvió emplazarlo, pero completando el importe con una suscripción popular ${ }^{23}$.

Por otra parte, encontramos en las palabras de un concejal una fundamentación más que sugerente sobre la designación de una calle en honor a Peralta Ramos:

"La historia de la ciudad señala lo que podríamos llamar dos períodos, característicamente definidos. El primero corresponde al esfuerzo magno de un hombre que, con la visión perfecta del

23 BRL, AL 24/5/1914. 
futuro, movido por el influjo de una concepción genial, se lanza a buscar en la pampa abierta e inhospitalaria un lugar que llegara en el porvenir a ser el asiento del núcleo urbano más opulento, entre las ciudades nuevas de la república, y el segundo al período constructivo de los continuadores del fundador y que encauzaron vigorosamente el progreso efectivo de esta comuna ¿Es justo que nuestras calles ostenten el nombre de otros hombres, muy dignos y muy meritorios, y se olvide al fundador, al ciudadano altruista a quien le debe el ser?"24.

Este concejal esgrimió una periodización de la naciente ciudad que la colocaba en un lugar privilegiado dentro del concierto argentino. Al incorporar a $\mathrm{M}$ ar del Plata en un escenario mayor se pretendía ratificar la unidad nacional al tiempo que, al ser destacado su caso como la materialización del progreso y la opulencia, sus autoridades encontraron un canal de legitimación de su poder ${ }^{25}$. Por otro lado, volvieron sobre la autonomía municipal al darse la tarea de suministrarle un lugar al fundador.

En resumidas cuentas pensamos que si el Centenario de 1910 permitió que el país estableciese un balance sobre lo actuado, el Centenario del nacimiento del "fundador" de Mar del Plata fue un espacio similar para los mandatarios marplatenses. Esto es porque reflexionaron sobre la evolución que esta ciudad "nueva" había desarrollado y sobre el rol que creían que ocupaba en la realidad nacional.

En este sentido advertimos también que celebraron el "festejo local" de 1914 implementando la misma dinámica que ya destacamos para los festejos patrios nacionales. En el programa se incluyeron además de la calle y el monumento señalado- otras actividades como: un Te Deum, ejercicios de acrobacia, corridas de sortijas, bailes nacionales, salvas de bombas, fuegos de artificio y retreta por una banda musical en la Plaza Principal, una función de gala en el Teatro Colón local para algunas familias, el reparto de fotograbados con su retrato, tranvías gratuitos durante todo el día, reparto de ropa y calzado por

\footnotetext{
24 Pal abras del concejal Columba, 27/5/1914. Citado en Barili (1964:82).

25 Centenario del Natalicio del fundador de Mar del Plata Don Patricio Peralta Ramos 1814 - 17 de mayo - 1914, Fiestas Conmemorativas, Mar del Plata, 1914: 5. En adelante Centenario Patricio Peral ta Ramos. La propia visión de las marpl atenses sobre la ciudad llevó también a que dos años antes una Comisión de vecinos la propusieran como capital de laArgentina. Ver Diario La Capital, Edición especial Bodas de Oro, Mar del Plata, 25 de mayo de 1955: 25.
} 
parte de los descendientes del "fundador" y un acto literario-musical en el Colegio Santa Cecilia ${ }^{26 .}$

Asimismo, la autoridad educativa local se hizo presente destacando la intervención de la familia Peralta Ramos en el desarrollo educativo marplatense ${ }^{27}$. Si le sumamos a esta última cuestión lo ya destacado sobre el reparto de ropa y calzado por parte de los descendientes de Peralta Ramos, volvemos sobre la legitimación de la élite dirigente en su voluntad de quedar en la memoria de la ciudad actuando sobre diferentes instancias de acción sociopolítica. O tro indicador de esta cuestión lo encontramos en el tratamiento que recibió el festejo por parte de la prensa provincial. El hecho de que el suceso repercutiese en la misma, muestra que lo que ocurría en $M$ ar del Plata no era ajeno al escenario bonaerense. Los principales diarios destacaron el rol primordial de la ciudad para la élite dirigente provincial, el mismo rol que las autoridades locales estaban gustosas de exteriorizar ${ }^{28}$.

De modo tal que podemos decir que la élite local repensó la identidad nacional a la luz de sus propios intereses, relacionados principalmente con la necesidad de ordenar y cimentar la sociedad y la estructura política local. Esta tarea se vio facilitada justamente porque tuvieron que reforzar una historia naciente lo que les dio un margen de acción mayor, al no tener que imponerse sobre una historia ya establecida. Esta cuestión se enlaza con otra que creemos central: la equiparación de Patricio Peralta Ramos a figuras nacionales. Efectivamente, si en primera instancia se afirmó que entre los nombres que habían sobrevivido a "la acción devoradora del tiempo" se encontraban Juan Martín de Pueyrredón, Manuel Rodríguez y Manuel Belgrano, dijo el Presbítero Artola:

"Permitidme ahora que a éstos hombres añada otro que brillará en el cielo de la gloria argentina, no fue conquistador pero fue

26 Centenario Patricio Peral ta Ramos, pp. 7 y 8. El Centenario del natalicio de Pedro Luro-cuya llegada en 1877 había dado impul so a la ciudad, dado que este sal aderista partici pó con capitales y una tecnología más moderna en las actividades productivas, trayendo consigo además el aporte de mano de obra de inmigrantes vascos- también fue festejado en la ciudad en 1920. El homenaje tuvo gran proyección y diversos actos. Citado en Barili (1964:125-127).

27 Discurso deJ ul io César Gascón. Citado en Barili (1964:84).

28 Por citar al gunos ejemplos, el periódico El Diario de BuenosAires destacó quesu padresirvió al regi miento "Patricios", que era amigo de Cornelio Saavedra mientras que la revista comercial La Defensa sugirió que era imprescindi ble erigir un monumento en homenajeal fundador de la que era la "meca estival de la élite porteña", Centenario Patricio Peralta Ramos, pp. 25 y 58 respectivamente. 
fundador, su nombre es D. Patricio Peralta Ramos. Persuadidos estáis que bien merece citarse este nombre entre los más célebres nombres" 29 .

Los grupos dirigentes marplatenses encontraron en Patricio Peralta Ramos un "padre fundador". Q uedaba así colocado en un panteón de héroes mayores y así también $M$ ar del Plata se insertaba en la historia nacional ${ }^{30}$. Si hacia fuera quedaba demostrado el progreso de la ciudad, hacia adentro se apuntaba a la consolidación de una identidad local necesaria para fortalecer el poder político.

\section{A modo de cierre}

El período comprendido entre 1880 y principios del siglo $X X$ fue de redefinición de la esfera socioeconómica y de conformación de la estructura política de Mar del Plata a la luz de su inserción en los procesos nacionales y provinciales. Ante relaciones sociales y políticas en proceso de institucionalización, sus autoridades convirtieron diversos elementos en prácticas políticas. Entre ellos, se sirvieron de los festejos patrios como instancias de integración social y de dominación política.

La conformación del poder político marplatense estuvo así enlazada a la construcción de un marco unificador de la identidad. La práctica patriótica de las autoridades en dichos festejos nació de la combinación de las disposiciones emanadas de un Estado nacional y provincial en consolidación y de la realidad de una ciudad en plena conformación. El refuerzo de la identidad nacional y la elaboración de una identidad local no entraron en contradicción ni fueron excluyentes. Ambas nutrieron tanto la afirmación de la unión nacional como la cohesión social y la legitimación del poder político de la ciudad.

29 Discurso del Presbítero Dr. Ramón Artola, Centenario Patricio Peralta Ramos, pp. 31-34.

30 Para el mismo período se ha analizado que en la ciudad de Córdoba, creada en 1573 pero en pleno proceso de reconstrucción, al gunos monumentos como las iglesias actuaron como memoria y otros lo hicieron como cimiento, en el marco de un conflicto político-ideológico local: el que enfrentaba a liberales y católicos. La burguesía cordobesa escogió el par José María Paz-Dalmacio Vélez Sarfield para simbolizar la presencia y el aporte de la ciudad a la organización nacional (Ansaldi 1996). 


\section{Referencias bibliográficas}

Álvarez, Adriana y Daniel Reynoso. "Las actividades económicas", en: AA.VV., Mar del Plata. Una Historia U rbana. Buenos Aires: Fundación Banco de Boston, 1991:67-92.

Ansaldi, Waldo. "Las prácticas sociales de la conmemoración en la Córdoba de la modernización, 1880-1914". Sociedad, № 8, 1996:95-127.

Barili, Roberto. Mar del Plata, ciudad de América para la humanidad. Mar del Plata: Ed. Municipalidad de General Pueyrredón, 1964.

_-_. Historia de Mar del Plata. Mar del Plata: Plus Ultra, 1991.

Bartolucci, Mónica (ed.) Mar del Plata. Imágenes urbanas, vida cotidiana y sociedad. 1874-1990. Mar del Plata: Área Editorial Departamento de H istoria, 2002.

Bertoni, Lilia Ana. "Construir la nacionalidad: héroes, estatuas y fiestas patrias, 1887-1891". Boletín del Instituto de Historia Argentina y Americana Dr. Emilio Ravignani, 3o serie, 1992:77-111.

. Patriotas, cosmopolitas y nacionalistas. La construcción de la nacionalidad argentina a fines del siglo XIX. Buenos Aires: FCE, 2001.

Chiaramonte, José Carlos. "El mito de los orígenes en la historiografía latinoamericana". Cuadernos del Instituto Ravignani, no 2, 1993:539.

Da O rden, María Liliana. Inmigración española, familia y movilidad social en la Argentina moderna. U na mirada desde Mar del Plata (1890-1930). Mar del Plata: Biblos, 2005.

___. "'Romerías españolas' e inserción social en tiempos de la inmigración masiva a la Argentina". A Grileira, no 5, 2003. http:// www.agrileira.com/unmeros/05/castellano/investigacion_05_ a.htm.

Ferrás, Liliana. "La figura del extranjero en el clima del centenario". IX Jornadas Interescuelas y Departamentos de Historia. Córdoba: Universidad Nacional de Córdoba, 2003. 
Jofré, Jorge, M aría Liliana Da O rden y Elisa Pastoriza. "La vida política", en: AA.VV., Mar del Plata. Una Historia U rbana. Buenos Aires: Fundación Banco de Boston, 1991:93-165.

Lanteri, Ana Laura. "Ritmos nacionales y compases locales: calles y monumentos en una ciudad 'nueva'. Mar del Plata (1880-1916)". Revista N exos, no 24, año 14, julio de 2007:24-30.

$M$ yers, Jorge. "A la nación por las fiestas: las fiestas mayas en el origen de la nación en el Plata". Boletín del Instituto de H istoria Argentina y Americana Dr. Emilio Ravignani, no 22, 2001:73-100.

Nora, Pierre. Les lieux de mémoire. Paris: Q uarto Gallimard, 3 vols., 1997.

Príncipe, Valeria. "Identidades locales y festejos nacionales: el caso de Rosario en 1910". IX Jornadas Interescuelas y Departamentos de Historia. Córdoba: Universidad Nacional de Córdoba, 2003.

Terán, O scar. "Nacionalismos argentinos (1810-1930)". Ciencias Sociales, no 1, 1994:31-40.

Ternavasio, Marcela. Municipio y política, un vínculo histórico conflictivo. La cuestión municipal en Argentina entre 1850 y 1920. Tesis de M aestría. FLACSO, 1991.

\section{Resumen}

N uestro objetivo en este trabajo es mostrar como, en el marco del proceso de consolidación de la nacionalidad iniciado a fines del siglo $X I X$, las autoridades de Mar del Plata encontraron en la celebración de los festejos patrios un resquicio para consolidar su poder y para definir una historia y una identidad para la novel ciudad. Emplearon diversos recursos para solemnizar dichos festejos, pero priorizaron y se sujetaron a las necesidades y urgencias de la comuna. Este hecho no fue visto como la desatención de su tarea patriótica, sino como una oportunidad que aprovecharon para legitimar su autoridad. La conformación del poder político marplatense estuvo enlazada a la construcción de un marco unificador de la identidad. Profundizamos el carácter y la historicidad del tema a partir de un análisis paralelo de la conmemoración de dos "Centenarios" desarrollados en la década de 1910, uno del orden nacional - el de la "Revolución de Mayo" de 1810- y 
el otro del orden local, el del natalicio del considerado fundador de la ciudad en 1814.

Palabras claves: nacionalidad, Mar del Plata, festejos patrios, "Centenarios", identidad.

\section{A nationality in consolidation and a city in construction. Patri- otic events in Mar del Plata between 1880 and 1916}

\section{Summary}

Our purpose in this work is to show how, within the frame of the process of consolidation of the nationality initiated by the end of $19^{\text {th }}$ century, Mar del Plata's authorities found in the patriotic events a crevice, to consolidate their power and to define a history and an identity for the new city. We show that they used diverse resources to solemnize the patriotic events, but prioritized to meet the needs and urgencies of the commune. This fact was not seen as carelessness towards its patriotic task, but as an opportunity to legitimize their authority. The conformation of the political power was connected to the construction of a unifying frame of the identity. We look deeply into the character and the historicity of the problem with a parallel analysis of the commemoration of two "Centenaries" developed in the decade of 1910, one of the national order - the commemoration of the " 1810 Revolution"- and the other of local order, the birth of the founder of the city in 1814.

Key words: nationality, Mar del Plata, patriotic events, "Centenaries", identity.

Recibido: 13/11/08; aceptado: 24/04/09. 